JANNASCH, H. W. (1958). J. gen. Microbiol. 18, 609-620

\title{
Studies on Planktonic Bacteria by Means of a Direct Membrane Filter Method
}

\author{
BY H. W. JANNASCH \\ Fluss-Station Freudenthal bei Witzenhausen, Germany* (der Hydrobiologischen \\ Anstalt der Max-Planck-Gesellschaft, Plön, Holstein)
}

SUMMARY: Direct observations on the occurrence and spatial distribution of planktonic bacteria were made by using a membrane filter technique. The membrane filters were treated to allow direct microscopic examination of bacteria on their surfaces. Deviations between direct counts on the membranes and plate (colony) counts of bacteria depended upon availability of organic matter in the natural waters studied, and can be accounted for by clumping effects and the occurrence of very small forms not visible on the membrane filter surfaces. Indirect evidence for these 'dwarf' forms was provided by later development of colonies with cells of normal size, after the membrane filter was placed on a nutrient medium. This response suggests that the organisms are zymogenous forms. Pure cultures of Bacillus subtilis and Pseudomonas fluorescens were used in some experiments to demonstrate the relationship between the clumping effect and concentration of dissolved nutrients in water. A concentration of $0.5 \mathrm{mg}$. peptone/l. in a tap-water medium caused accumulations of bacteria around clean chitin particles; accumulations of bacteria did not develop at the higher concentrations tested. This behaviour is explained by the local differences in concentrations of nutrients in the medium. It correlates with the observations on natural populations.

The nutritional factor determines not only the distribution of bacteria in natural waters, but also the methods available for their demonstration. Only enriched substrates yield readily measurable bacterial growth and metabolic products in laboratory cultures as well as in nature. The lack of direct indicators of quantity of bacterial growth in media very poor in nutrients may have been a cause for much more work being done on the bacteria of bottom deposits of natural waters as compared to the planktonic forms.

In uncontaminated natural waters the concentration of dissolved organic matter is generally low, but when suitable solid or colloidal organic matter is present, individual bacteria may be confronted with higher concentrations of nutrients. By means of largely unknown and complex adjustments, natural populations of bacteria are able to decompose organic compounds over a wide range of concentration and composition. In the same way that bacterial populations adjust to natural conditions, they adjust to artificial conditions of cultivation. Consequently, it is impossible to determine their original activity after transfer to a medium enriched in nutrients. This means of increasing the formation of reaction products is integral to most of the general methods of estimating the quantity of bacteria. If any process is involved whereby metabolism is promoted, the method should be defined as indirect and the results applied with caution to ecological problems (Gibson, 1957). The

* Present address: University of California, Scripps Institution of Oceanography, La Jolla, California, U.S.A. 
use of pure cultures avoids a part of selective adaptation but involves conditions far removed from those affecting natural mixed populations.

Enumeration of organisms is still the 'most sensible index' (Waksman), and the usual method for assessing the activity of the bacterial population in water or soil, although the relations between growth, cell-multiplication, and respiration may vary. The culture plate (colony count) method is, according to our definition, indirect. In order to employ the advantages of the direct method, the counting of organisms on microscopic preparations, the use of membrane filter techniques is discussed in this paper. A description of some specific applications is given and the results from these are considered in relation to the ecological status of planktonic bacteria.

\section{DIRECT OBSERVATION OF PLANKTONIC BACTERIA}

Counts of planktonic bacteria have been obtained by exposing glass slides to the natural medium. Micro-organisms grow on the surface and can be counted microscopically, after preparation, in relation to a unit of exposure time. Previously used for algae (see Lund \& Talling, 1957), this method was first applied in soil by Cholodny (1930) and in water by Karsinkin (1934). Although it has been considered a direct method (Henrici, 1933), this view does not accord with the definition above, since the surface properties of the slides promote growth of attaching bacteria and cause a selection of sessile forms (ZoBell, 1943). Finally, this method does not permit an estimate of microorganisms in a unit area or volume of the original habitat. The difficulty of direct methods is that no distinction is possible between living and dead cells. Nevertheless, experiments by Strugger (1949) on organisms in natural environments, with acridine orange to differentiate between living and dead protoplasm, showed that in the examples studied the percentage of dead cells was low. The rate of growth depends on the concentration of organic matter available, as found by Zavarzina (1955).

The direct methods of enumeration of bacteria in liquids depend mainly upon the population density of the suspensions and the visibility (i.e. size, arrangement and staining reaction) of the individual forms. For most natural waters, a satisfactery means of concentrating the samples is necessary before microscopic observation. Earlier successful approaches were made by Kunznetsov \& Karsinkin (1931), who used evaporation under reduced pressure and by Cholodny (1928, 1929), who used filtration, both procedures yielded much higher counts of bacteria than were found by the plating method. The microscopic counting of bacteria in a minute capillary tube of glass after concentration in vacuo was described by Collins \& Kipling (1957).

\section{The direct membrane filter method}

Cholodny (1928) used membrane filters to concentrate bacteria in river water; he streaked the residue on slides. Rasumov (1932) used Cholodny's method but tried to observe the filtered micro-organisms directly on the membrane filter surface. The membrane filter was rendered transparent by 
immersion oil. This membrane filter technique has been improved and described in detail (Jannasch, 1953; virtually the same technique was reported by Ehrlich, 1955), and was used in the present study. Briefly the membrane filter (from Membranfilter Gesellschaft, Göttingen, Germany) was treated as follows. After filtration of different dilutions of the sample, the organisms on the membrane filter surface were fixed (e.g. with $10 \%$ formaldehyde) and stained (e.g. with Löffler's methylene-blue, or phenol (5\%) + erythrosin (1\%)) by laying the membrane filter on the surface of the staining solution in a Petri dish. The filter material has been decolorized by washing with filtered distilled water to promote an optical contrast. Before each of these three steps, the membrane filter was dried; temperatures up to $90^{\circ}$ can be used. By means of a special apparatus the membrane filter surface can be divided into 19 parts, each for the filtration of one sample, or of several dilutions of one sample, at the same time. The prepared membrane filter is then dissected, placed on slides, and rendered transparent by a mixture of caedax (Merck)+liquid petrolatum (ratio 1:1), or liquid petrolatum $+\alpha$-bromonaphthalene + eugenol (ratio 5:2:2). The refractive indices of these mixtures are adjusted to approach that of the membrane filter used. The standard error of the direct counts has been improved by increasing the number of microscope fields counted. In extreme cases of heterogeneous distribution of organisms, up to 120 microscope fields/membrane filter have been enumerated. A grid of 16 square fields was used at $\times 800-1000$ magnification.

The spatial arrangement of the bacteria in the sample becomes projected on the membrane filter surface. The best results were obtained with pure cultures in the logarithmic phase of growth (Butkevich, 1938), with which the counting error was as low as $4-6 \%$ (Jannasch, 1953), due to the even distribution and size of the organisms. In media rich in nutrients, multiplication became apparent before any visible change in optical density occurred.

The general limit of this method, depending on technique and experience, is the visibility of micro-organisms on the membrane filter surface. The main advantage is that concentration of the sample and preparation for microscopic observation are combined in one operation. A valuable feature for field studies is the possibility of fixing and drying the membrane filters by a short process, and storing them for the subsequent preparation and examination in the laboratory.

When the filters are placed on pads of coarse adsorbent paper soaked with a solution of nutrients, this method can be used for cultural purposes (for detailed description see p. 617). For field studies, the pads were soaked in nutrient solution, dried, sterilized in the laboratory. Before use they were saturated with sterile distilled water, conveniently kept in a wash bottle with cotton-wool filter. On ships the rocking motion or the vibration of the engine does not prevent the use of these culture plates.

\section{RESULTS}

When the method described was applied to natural waters, and the results compared with those obtained by plating, some interesting relationships appeared concerning the occurrence and spatial distribution of planktonic 
bacteria. When the bacterial population densities in waters of varied nutrient content were estimated, then with the exception of very clean waters the direct counts exceed the plate counts (Table 1). This seems to be explicable from the microscopic evidence.

In offshore sea water, bacteria were found in groups, often attached to particles (Pl. 1, fig. 1a). Here the direct count can be only roughly estimated. As applied in direct counting methods of soil bacteriology (Strugger, 1949), correction factors of 10,50 , or 100 have been used to allow for clumping. Obviously only one colony can be formed on the culture plate regardless of the number of organisms in a clump. These clumps did not occur in the very contaminated sea water studied, where distribution was more homogeneous (Pl. 1, fig. $1 b$ ) and almost every individual bacterium can be distinguished. In this case the effect of selection may be chiefly responsible for the lower plate count. Samples of contaminated river water showed a similar picture (Pl. 1, fig. 2b). When spring water was filtered, however, it was difficult to identify bacteria clearly by their morphological form of arrangment on the membrane filter surfaces (Pl. 1, fig. 2a). Different staining methods were used, including differentiation between inorganic and organic material by staining with phenol-erythrosin or water-blue, but without success. When water of the same sample was plated a considerable number of colonies grew. Consequently individuals capable of proliferation must have been present in the spring water. The bacteria of the plate colonies show the normal size and would have been easy to detect on the membrane filter surface.

In the following experiments the two methods were combined to obtain some insight into the early stages of development of these colonies. After filtration of the spring water, a part of the membrane filter was prepared as usual. The remaining part of the membrane filter was laid in a Petri dish on sterile pads of absorbent paper soaked with a sterile solution of the following composition : glucose $150 \mathrm{mg}$.; peptone $50 \mathrm{mg}$; y yeast extract $5 \mathrm{mg}$.; tap water 1 l.; $\mathrm{pH} \mathbf{7 \cdot 2}$, and incubated at $22^{\circ}$. From hour to hour a part of the filter membrane was removed and prepared. In this way the formation of colonies of only a few organisms (micro-colonies) was observed (Pl. 1, fig. 3). These colonies must have originated from bacterial forms previously not detectable on the membrane filter surface by microscopic examination. The organisms of the micro-colonies were similar in size and shape to those grown on the nutrient agar plates. In some comparable observations, Strugger (1949) isolated coccoid forms of $1 \mu$. diameter from soil directly, and watched microscopically their development to rods 5-7 $\mu$. long in hanging-drop peptone water culture. Radzimovsky (1930), using Cholodny's direct method, also found very small 'non-countable' bacterial forms in most of the waters he studied. Although in the present experiments the evidence is still indirect, the presence is suggested of very small or 'dwarf' forms, able to develop into larger forms after transfer into nutrient media. From the morphological viewpoint they may correspond to the group of micro-organisms which are defined as 'zymogenous' by Winogradsky (1925).

By means of the same technique they have also been found in other types 
of clean waters. In Table 1 the number of organisms visible on the membrane filter surface before cultivation has been subtracted from the number of micro-colonies determined after incubation for $6 \mathrm{hr}$. at $22^{\circ}$. After $10 \mathrm{hr}$. the colonies begin to grow together (Pl. 1, fig. $3 b$ ); this may also be a factor tending to decrease the plate counts. The occurrence of dwarf forms, or the formation of micro-colonies in the way described, may have important ecological implications. Their number (see Table 1) appears inversely correlated with the contamination of the water, as estimated (Vinberg \& Platova, 1951) by the oxidative determination of reduced material with permanganate. The

Table 1. Counts of bacteria, in various types and zones of natural waters, obtained by plating and by the direct membrane filter method

The plate counts of sea water were obtained on medium $2216 \mathrm{E}$, suggested by Oppenheimer \& ZoBell (1952). Instead of aged sea water, tap water was used for plating freshwater samples.

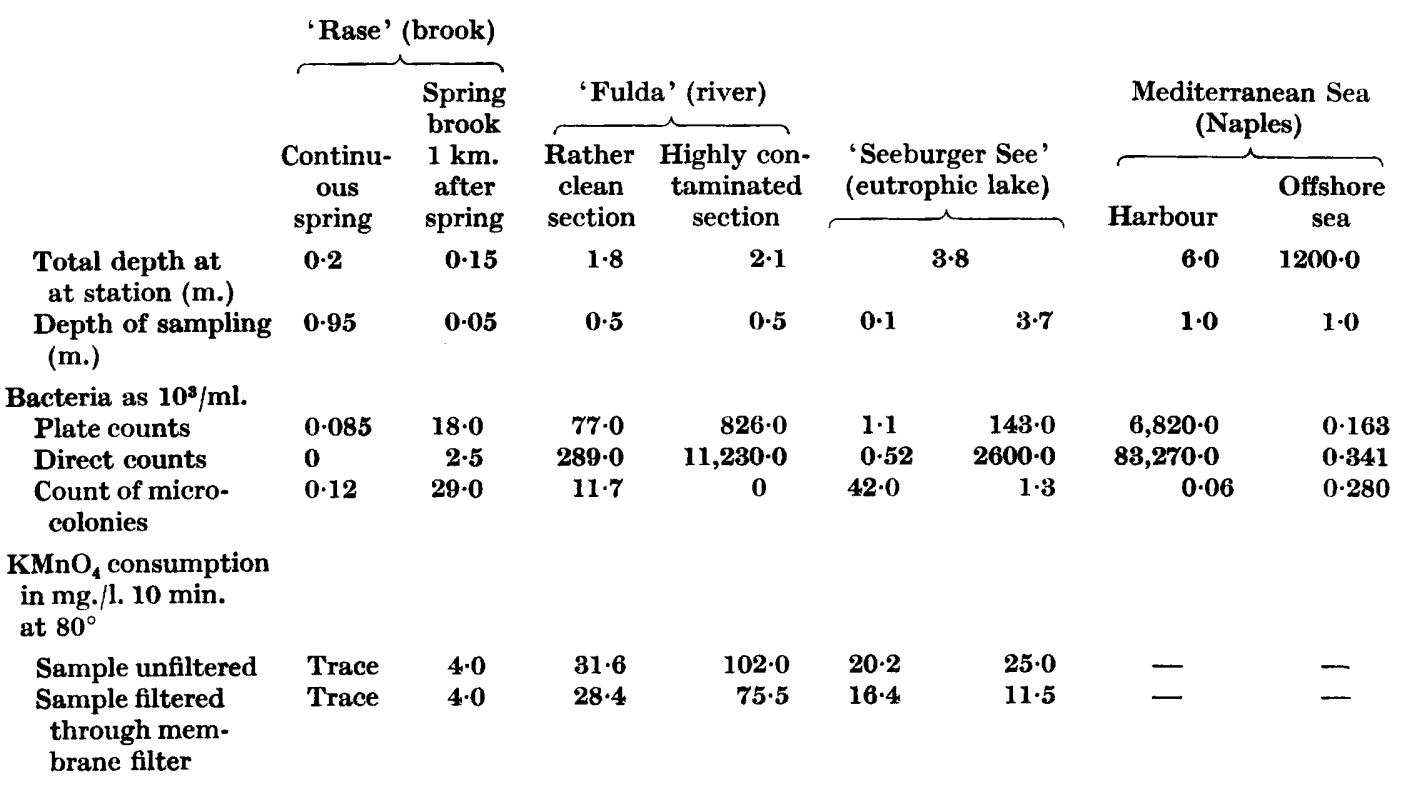

absence of Gram-positive pleomorphic bacteria was established by Taylor (1942) for natural waters and suggested as the main difference from microflora of soil. The statement could not be confirmed for the types of water studied as shown above.

In addition to the clumping effect in pure waters, a similar feature occurs in waters rich in particulate nutrients. Bacteria were seen growing on the surface of detritus particles which apparently contain amounts of decomposable organic matter (Pl. 2, fig.4). Direct enumeration or, at least, some estimation by counts of organisms in such associations is possible.

Direct observation also readily permits morphological studies. Radzimovsky (1930) and Beling (1950) compared the occurrence of different morphological types of bacteria in river waters of different grades of contamination 
by cultivation and by direct methods. In all cases the percentage of rods was much higher on the culture plates than in the direct counts. Radzimovsky concluded that more species of coccal forms belonged to the autotrophic and organophobic group, unable to grow on the culture medium used. Besides this selective effect, variations in size and form of the organisms during cultivation may also occur, as shown above. Plate 2, fig. 4a, shows irregular coccoid forms frequently to be found in filter preparations of water from the upper layer of an eutrophic lake (the Seeburger See). They were not obtained in various media on culture plates, even Azotobacter-enriching medium being used without success. Unfortunately, the preparation of the membrane filter for direct observation prevents the isolation of individual organisms and further studies of pure cultures. Spirilla, also difficult to grow for quantitative evidence, have been found near or attached to detritus particles (Pl. 2, fig. $4 b$ ).

\section{OBSERVATIONS ON BACTERIAL AGGREGATES}

\section{Aggregation and nutrient supply}

The distribution of planktonic bacteria on the membrane filters suggests that the main source of error in the plating method may be the clumping effect. According to ZoBell \& Anderson (1936), Stark, Stadler \& McCoy (1938), and others, the attachment of bacteria to suspended solid surfaces follows a previous adsorption of soluble organic matter. The effect on the growth of bacteria depends upon the concentration of soluble nutrients present, as shown by Heukelekian \& Heller (1940), who measured the amounts of adsorbed organic matter by means of an oxidizing reagent. Some experiments involving a modified membrane-filter technique are described below. They illustrate the influence of small concentrations of dissolved nutrients, in the presence of particulate material, upon the distribution of planktonic bacteria.

Chitin obtained from crab shells was cleaned (Stanier, 1947) and homogenized. Particles of $c .10-50 \mu$. in diameter were obtained by fractional centrifugation. About 500-1000 particles/ml., determined microscopically, were added to sterile-filtered tap water. Organisms from a newly isolated culture of Bacillus subtilis were washed, collected on a membrane filter, and added to the suspension of chitin particles in a density of about 10,000 organisms $/ \mathrm{ml}$. Parallel cultures were incubated at $22^{\circ}$ in 21 . Fernbach flasks after addition of different concentrations of peptone $(0,0 \cdot 1,0 \cdot 5,1 \cdot 0,5 \cdot 0,10 \cdot 0,25 \cdot 0 \mathrm{mg} / 1$. $)$. Continuous shaking prevented sedimentation. No decomposition of chitin by this organism was observed in previous control experiments. At half-day intervals plate counts and direct counts were made.

Three significant concentrations of peptone are chosen in the following description of the findings. The greatest deviation between the plate and direct counts occurred when $0.5 \mathrm{mg}$. peptone/l. was added (Fig. 1). After 5-6 days the plate count decreased while multiplication was still indicated by the direct observations. The inoculated organisms, at first uniformly distributed on the membrane filter surface, ceased their initial proliferation after about 6 days. Spores began to appear after 8 days in $30-40 \%$ of the cells. Basophilic sub- 
stances inside the cells disappeared, as indicated by vital methylene-blue staining. Between 6 and 8 days bacteria again multiplied, but now on or near the chitin particles. At this stage the membrane preparations appeared as illustrated in Pl. 1, fig. $1 a$. The arrangement of organisms in relation to the chitin particles often suffered some alteration from the filtration process.

In contrast with the effects with $0.5 \mathrm{mg}$. peptone $/ \mathrm{ml}$. no clumping effect was observed with tap water alone, nor in the medium containing $5.0 \mathrm{mg}$.

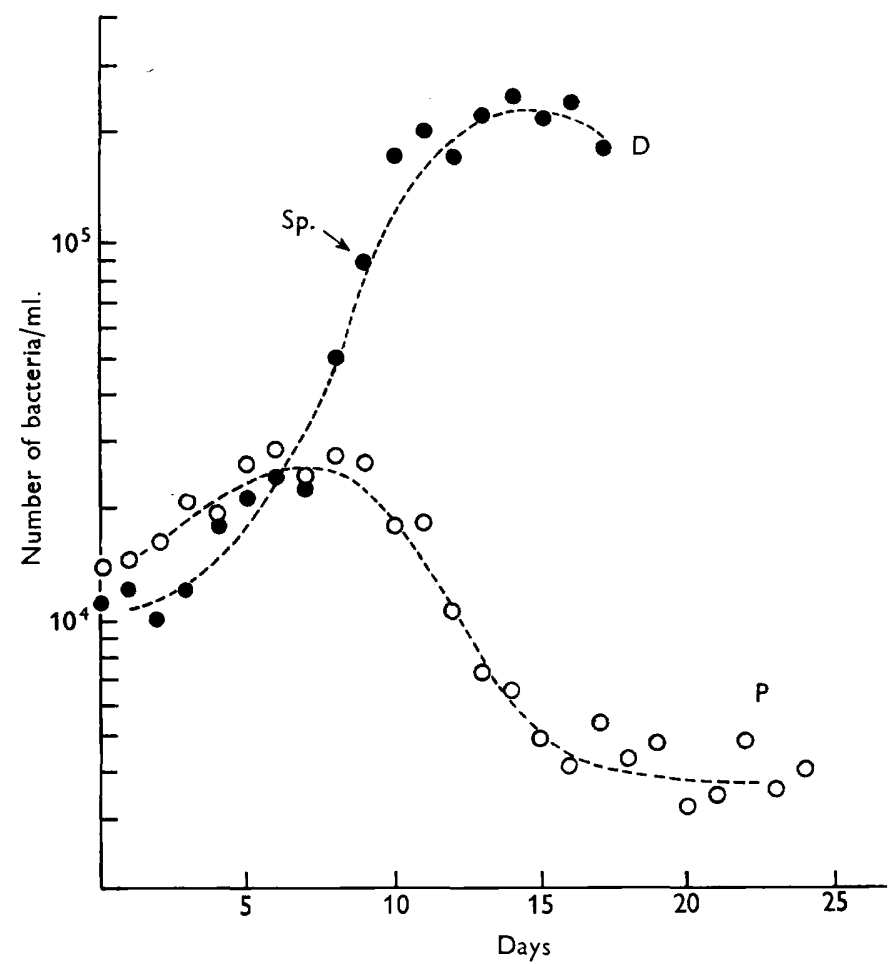

Fig. 1. Direct counts (D) and plate counts (P), per ml., of Bacillus subtilis in tap-water media containing $0.5 \mathrm{mg}$. peptone $/ \mathrm{l}$. (Sp. =appearance of spores.)

peptone/l. In both cases the distribution of organisms showed no relationship to the suspended particles; this is illustrated schematically in Fig. 2. The initial multiplication of cells in the tap-water medium without nutrients may be due to reserve substances; the formation of spores here began after only 2 days. A concentration of $\mathbf{5 . 0} \mathrm{mg}$. peptone/l. seems to be sufficient for direct uptake from the solution of the offered nutrients by the bacteria. In this case, the difference of nutrient concentrations as between the bulk solution and the particle surfaces may not have been sufficient to show a heterogeneous distribution of the growing bacteria. The existence of a sufficient difference may cause the clumping effect described above.

In several cases growth occurred on suspended chitin particles in media 
containing only $0.1 \mathrm{mg}$./peptone/1., but not before 4-5 weeks. Flocculent aggregates appeared in media containing more than $20 \mathrm{mg}$. peptone/l. and were formed of connected chains of organisms.

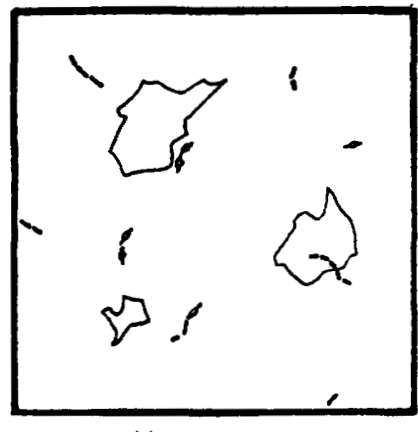

No peptone

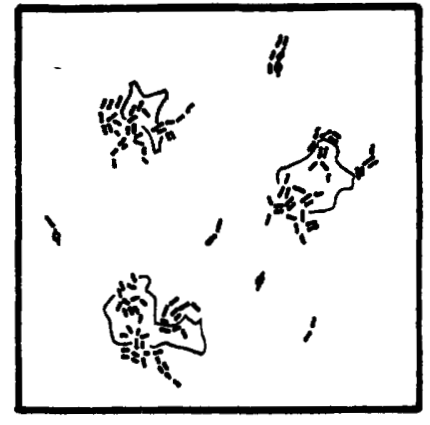

$0.5 \mathrm{mg}$. peptone/l.

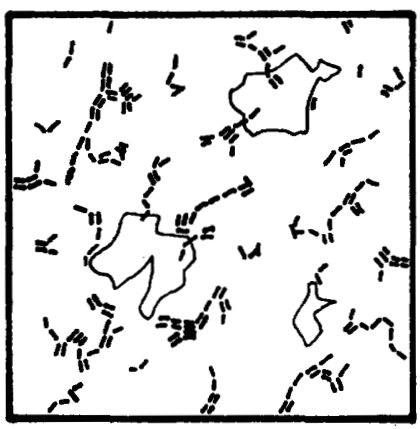

$5.0 \mathrm{mg}$. peptone/l.

Fig. 2. Distribution of cells of Bacillus subtilis after incubation for 8 days at $22^{\circ}$ in tapwater media containing cleaned particles of chitin and different concentrations of peptone. Schematized from microscopical preparations of membrane filters. Using a grid of 16 fields per square above, the standard errors for the count of the three cultures were $1 \cdot 2,5 \cdot 6$ and $0.7 \%$.

\section{Aggregation of particulate material}

As compared with the dissolved phase, solid residues of plant and animal tissue must often offer higher concentrations of nutrients to the micro-organisms of a natural medium. There particles may undergo disintegration by the 'zymogenous' component of bacterial flora consisting of actively fermenting bacteria and fungi. These organisms may generally exist in a dormant state as spores or their equivalents. If soluble nutrients emerged locally, rapid fermentation processes might occur and large numbers of organisms be formed. After consumption of the energy source, the numbers of vegetative forms would decrease and new resting cells develop. This description was accepted and completed by Conn (1948), especially for the micro-flora of soil. The following experiments (labelled $a, b, c$ ) concern the growth of inoculated bacteria in a suspension of particulate nutrients, or of nutrients adsorbed on 
particulate material. They are intended as 'models' of similar events in natural waters.

(a) Suspensions of washed organisms from pure cultures of Bacillus subtilis and Pseudomonas fluorescens, isolated from water, were stored in tap-water medium, sterilized by filtration, for 4 months. Only a few spores were found microscopically after this period in the culture of $B$. subtilis. Then diatoms, obtained by enrichment culture and killed by heat, were suspended as the sole energy source in the inoculated tap-water medium. The cultures in 21. Fernbach flasks were stored at $\mathbf{2 2}^{\circ}$ and shaken to prevent sedimentation. The growth of bacteria was observed by means of the direct membrane-filter method.

(b) In some parallel experiments, cleaned chitin particles were used instead of dead diatoms. They were enriched nutritionally by exposure for 4-6 days in a nutrient solution of the composition given on page 612, but increased tenfold in concentration. To avoid a rapid diffusion of nutrients into the culture media, the cultivation took place on the membrane filter surface. The enriched chitin particles were filtered together with the suspension of bacteria. The membrane filter was then placed on a paper pad saturated with sterile tap water and incubated under the same conditions as the liquid cultures. After different periods the membrane filters were prepared as usual for microscopic observation.

(c) The conditions of the last experiment were modified to test a possible effect of non-enriched particles on bacterial growth. Cleaned chitin particles and the suspension of bacteria were filtered and the membrane filter placed on paper pads soaked with the nutrient solution.

In the liquid cultures (Expt. $a$ ) of both species of bacteria used, groups of bacteria appeared close to the diatoms after 10-24 $\mathrm{hr}$. When in comparative experiments, acid-cleaned diatom shells were suspended, no bacterial growth was observed. Dense growth appeared after raising the concentration of dissolved nutrients in the water to more than $10 \mathrm{mg}$. peptone/l., but no clumping occurred, due to the effect of a high enough bulk concentration of nutrient, mentioned earlier.

The same general picture was observed in the membrane filter cultures (Expt. b). Rods of the two organisms tested grew next to the chitin particles (Pl. 2, fig. 5) as well as to the diatoms. The membrane filter preparations do not permit the continuous observation of morphological changes in the same colony. Consequently, it was difficult to follow the second process in development of the zymogenous forms, namely the re-forming of the dormant stage. Some observations on this subject have already been described (Jannasch, 1955).

Particles lacking any added nutrients (Expt. $c$ ) showed no influence upon the distribution of bacteria growing on the membrane filter surface. The bacteria multiplied with a uniform distribution, as shown in Pl. 2, fig. 6. This picture probably corresponds with the third sketch in Fig. 2, although in those experiments the bacterial growth took place in suspension. After a period of 6-8 days, the membrane filters became overgrown and no individual cell could be distinguished. 


\section{DISCUSSION}

The foregoing observations show that the direct membrane-filter method, as applied in this paper, fails to give total counts; this is due to the occurrence of forms which are difficult to distinguish microscopically on the membrane surface. The development of micro-colonies after addition of nutrients shows that small forms escape observation. Small coccoid forms, on the other hand, are characteristic of the indigenous micro-flora of natural substrates, according to Conn (1948). His definition of the autochthonous (indigenous) group of soil bacteria may be helpful in estimating which type of organism becomes selected and reported by the direct method. He considers the autochthonous micro-flora to include mainly small forms which represent stages in the life cycle of bacteria that are normally rod-shaped (Arthrobacter). Similar but nonpleomorphic short rods are collected in the genus Agrobacterium Conn. According to Radzimovsky's findings, Conn considers most of the micrococci found in untreated soil as stages of rod-shaped bacteria. Physiologically, the autochthonous bacteria are defined as possessing a weak fermentative ability.

As regards morphological characteristics, all bacterial forms observed directly in pure waters seem to belong to the autochthonous micro-flora. However, the ability of some to develop on concentrated nutrients in a relatively short period would require their classification as zymogenous forms of abnormally small size. From this viewpoint the term 'dwarf forms' seems to be justified. A still unanswered question is whether or not non-spore-forming zymogenous bacteria have a dormant form which is functionally equivalent to a spore. Its existence, even in forms belonging to spore-forming bacteria, is probable, since spores were rarely found on the membrane filter directly when later many colonies grew after cultivation. Despite the limitations of the direct observations, the high counts obtained in often very pure waters suggest that indigenous bacteria are included, although there is no conclusive evidence.

My thanks are due to Dr J. F. Talling for helpful criticism of the manuscript.

\section{REFERENCES}

BeLing, A. (1950). Bakteriologische Untersuchungen während der Fulda Expedition 1948. Ber. Limnol. Flusstat. Freudenthal, 2, 4.

Butkevich, V. S. (1938). On the bacterial population of the Caspian and Asov seas. Microbiology, Moscow, 7, 1005.

Cholodny, N. (1928). Contributions to the quantitative analysis of bacterial plankton. Trav. Sta. biol. Dniepre, 3, 157.

Cholodny, N. (1929). Zur Methodik der quantitativen Erforschung des bakteriellen Planktons. Zbl. Bakt. (Abt. 2), 77, 179.

Cholonny, N. (1930). Über eine Methode zur Untersuchung der Bodenmikroflora. Arch. Mikrobiol. 1, 620.

Collins, V. G. \& KrPling, C. (1957). The enumeration of waterborne bacteria by a new direct count method. J. appl. Bact. $20,2$.

ConN, H. J. (1948). The most abundant groups of bacteria in soil. Bact. Rev. 12, 257.

EHRLICH, R. (1955). Technique for microscopic count of micro-organisms directly on membrane filters. J. Bact. 70, 265. 
Gibson, J. (1957). Nutritional aspects of microbial ecology. Symp. Soc. gen. Microbiol. 7, 22.

Henrici, A. T. (1933). Studies of freshwater bacteria. I. A direct microscopic technique. J. Bact. 25, 277.

Heukelekian, H. \& Heller, A. (1940). Relation between food concentration and surface for bacterial growth. J. Bact. 40, 547.

JaNNASCH, H. W. (1953). Zur Methode der quantitativen Untersuchungen von Bakterienkulturen in flüssigen Medien. Arch. Mikrobiol. 18, 425.

JANNASCH, H. W. (1955). Zur Ökologie der zymogenen planktischen Bakterienflora natürlicher Gewässer. Arch. Mikrobiol. 23, 146.

Karsinkin, G. S. (1934). Zum Studium des bakterialen Periphytons. Arb. limnol. Sta. Kossino, 17, 21.

Kuznetsov, S. \& Karsinkin, G. S. (1931). Direct method for the quantitative study of bacteria in water and some considerations of the causes which

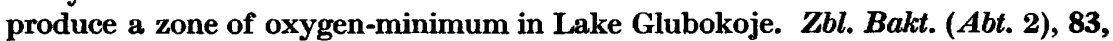
169.

Lund, J. W. G. \& TALLING, J. R. (1957). Botanical limnological methods with special reference to the algae. Bot. Rev. 23, 489.

Oppenheimer, C. H. \& ZoBell, C. E. (1952). The growth and viability of sixtythree species of marine bacteria as influenced by hydrostatic pressure. J. mar. Res. $1,10$.

Raczimovsky, R. (1930). Vorläufige Angaben über die Dichtigkeit der bakteriellen Besiedlung einiger Gewässer. Trav. Sta. biol. Dniepre, 5, 385.

Rasumov, A. S. (1932). Die direkte Methode der Zählung der Bakterien im Wasser und ihre Vergleichung mit der Kochschen Plattenkultur Methode. Microbiology, Moscow, 1, 131.

Stanier, R. Y.(1947). Studies on nonfruiting myxobacteria. I. Cytophaga Johnsonae, n.sp., a chitin decomposing myxobacterium. J. Bact. 53, 297.

Stark, W. H., Stadler, J. \& MCCoy, E. (1938). Some factors affecting the bacterial population of freshwater lakes. J. Bact. 36, 653.

StrugGer, S. (1949). Fluorescensmikroskopie und Mikrobiologie. Hannover: M. v. H. Schaper.

TAYLOR, C. B. (1942). Bacteriology of freshwater. III. The types of bacteria present in lakes and streams and their relationship to the bacterial flora of soil. J. Hyg., Camb. 42, 284.

Vinberg, G. G. \& Platova, T. P. (1951). Biomass of plankton and the dissolved organic matter in lake water. Bjull. Moscov. Obsc. Ispyt. Prir. N. S. Otdel. Biol. 56, 24.

Winogradsky, S. (1925). Etudes sur la microbiologie du sol. I. Sur la méthode. Ann. Inst. Pasteur, 39, 299.

Zavarzina, N. B. (1955). A study of the factors inhibiting the development of microorganisms in the thick silt deposits of Lake Biserovo. Microbiology, Moscore, 24, 573.

ZoBeLl, C. E. (1943). The effect of solid surfaces upon bacterial activity. J. Bact. 46, 39.

ZoBell, C. E. \& ANderson. D. Q. (1936). Observations on the multiplication of bacteria in different volumes of stored sea water and the influence of oxygen tension and solid surfaces. Biol. Bull., Woods Hole, 71, 324. 


\section{EXPLANATION OF PLATES}

The membrane filters were stained with phenyl-erythrosin in Figs. $1 a, 2 a, 4 b$ and 5 ; in other figures they were stained with Löffler's methylene-blue.

\section{Plate 1}

Fig. 1. Membrane filter preparations of ( $a$ ) offshore sea water, and (b) highly contaminated harbour water from the Mediterranean at Naples. The volumes filtered were in the ratio 400:1. (From H. W. Jannasch, 1954, Naturwissenschaften, 41, 42.)

Fig. 2. Membrane filter preparation of $(a)$ spring water (the Rase) and (b) contaminated river water (the Fulda). The volumes filtered were in the ratio $600: 1$.

Fig. 3. Membrane filter preparations of micro-colonies grown after filtration of spring water and an incubation of $(a) 5 \mathrm{hr}$. and (b) $10 \mathrm{hr}$.

\section{Plate 2}

Fig. 4. Membrane filter preparations of detritus particles from the upper layers of the Seeburger See.

Fig. 5. Growth of Pseudomonas fluorescens on membrane filter close to particles of chitin enriched with peptone.

Fig. 6. Cells of Bacillus subtilis uniformly distributed on a membrane filter, which had been placed on paper pads soaked with nutrient solution.

(Received 15 November 1957) 
Journal of General Microbiology, Vol. 18, No. 3
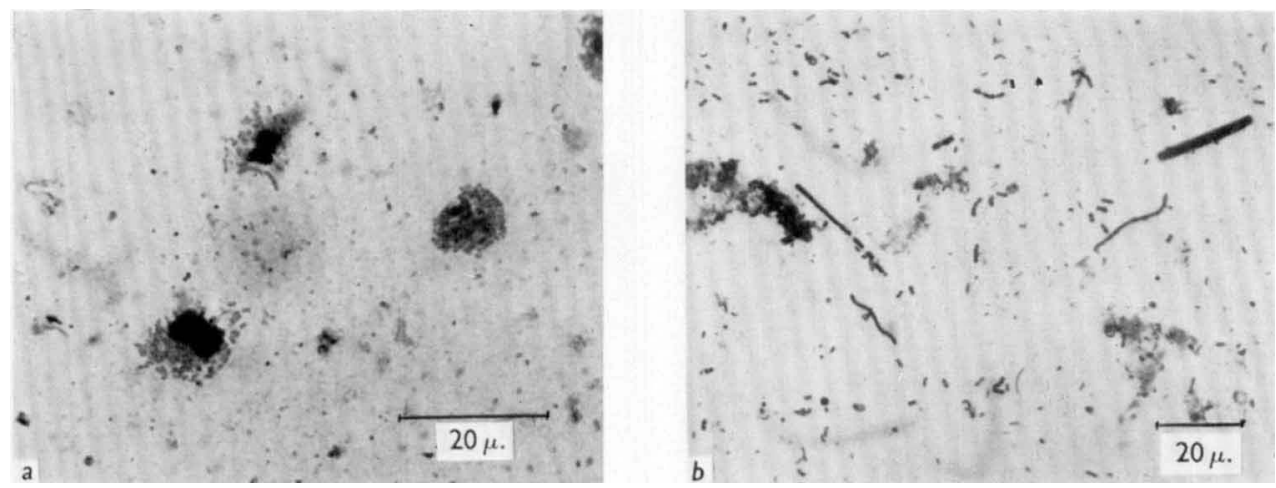

Fig. 1
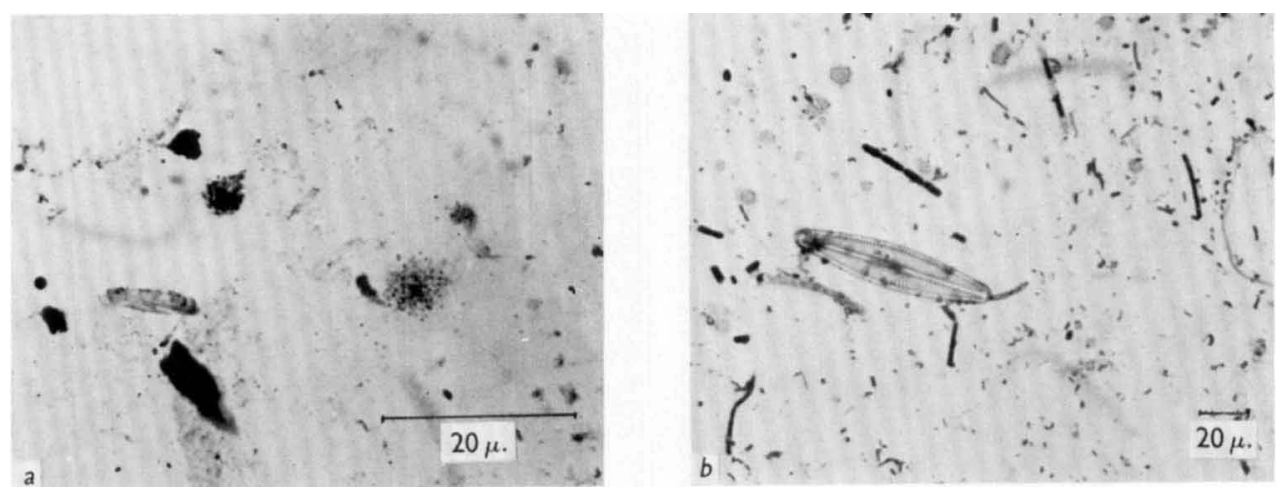

Fig. 2
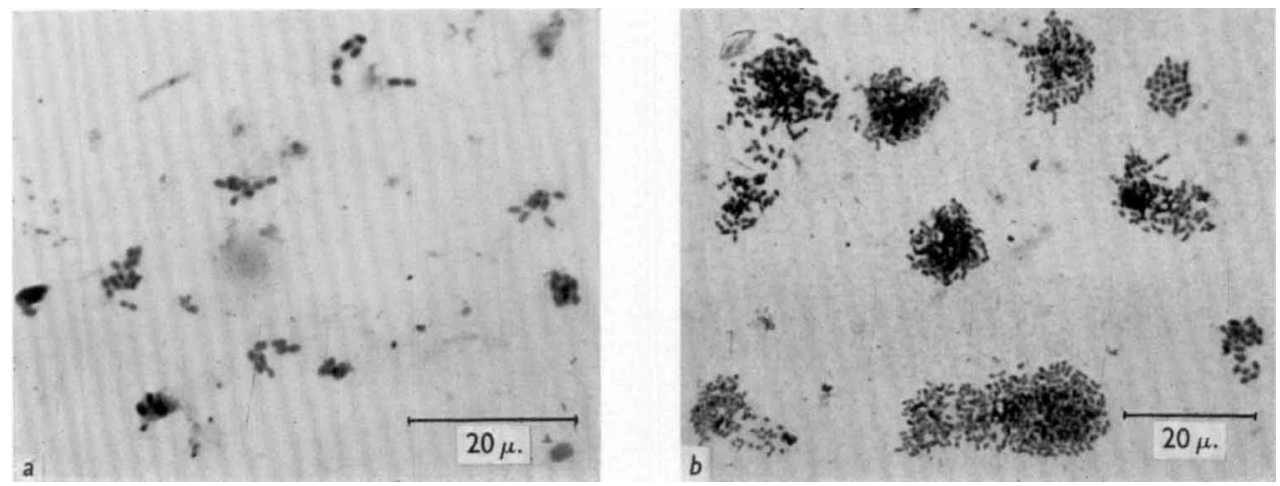

Fig. 3

H. W. Jannasch-Studies on planktonic bacteria. Plate 1

(Facing p. 620) 
Journal of General Microbiology, Vol. 18. No. 3

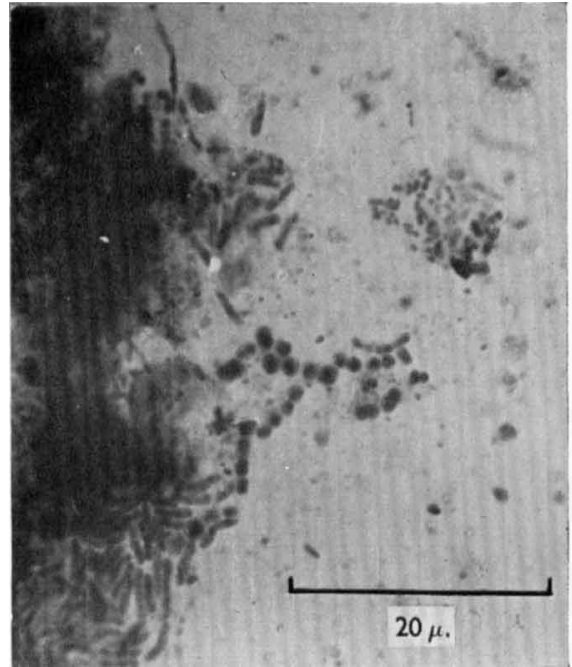

Fig. $4 a$

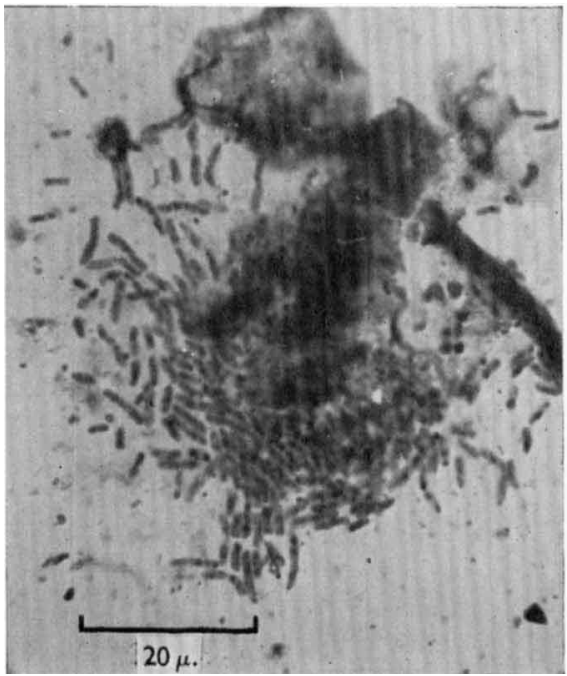

Fig. 5

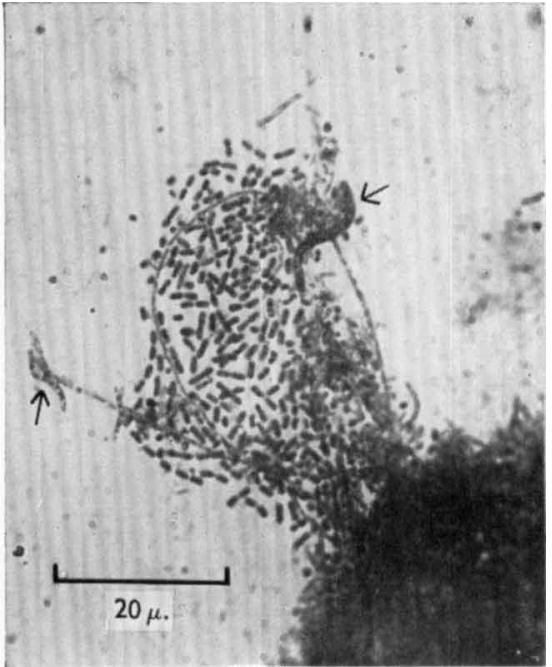

Fig. $4 \cdot b$

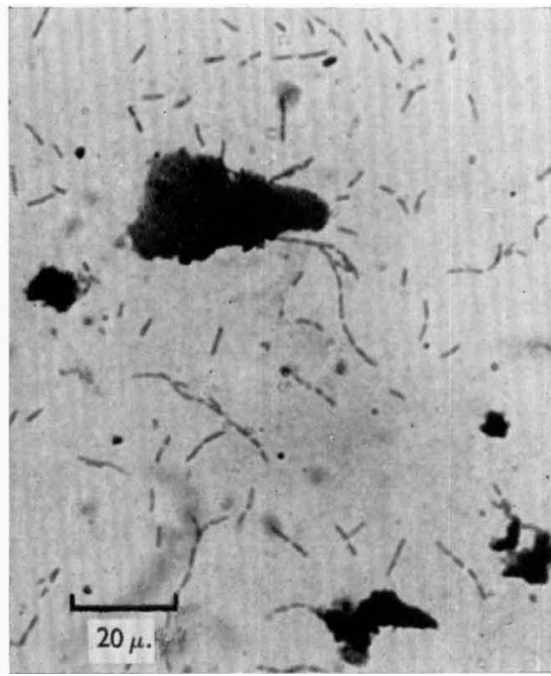

Fig. 6

H. W. Jannasch-Studies on planktonic bacteria. Plate 2 